\title{
Combustion Emissions Modeling and Testing of Conventional Diesel Fuel
}

\author{
H-P. Liu ${ }^{1}$, S. Strank ${ }^{1}$, M. Werst ${ }^{1}$, R. Hebner ${ }^{1}$, and J. Osara ${ }^{2}$ \\ ${ }^{1}$ Center for Electromechanics, University of Texas at Austin, Austin, TX 78712 \\ ${ }^{2}$ Department of Mechanical Engineering, University of Texas at Austin, Austin, TX 78712
}

\begin{abstract}
This paper presents emissions modeling and testing of a four-stroke single cylinder diesel engine using conventional No. 2 diesel fuel. A system level engine simulation tool developed by Gamma Technologies, GT-Power, has been used to perform engine combustion simulations. The simulation approach is a predictive combustion simulation, direct-injection jet modeling, which is primarily used to predict the burn rate and $\mathrm{NO}_{\mathrm{x}}$ emissions.

Crank angle dependent fuel injector sac pressure profiles have been measured during combustion tests and used as fuel jet inputs in the combustion modeling to predict injected fuel mass and fuel jet velocity as a function of time. In each emissions test, an in-cylinder pressure profile was measured and used for combustion model calibration to assure a correct burn rate profile was predicted and the exhaust emissions prediction was based on a calibrated burn rate profile which closely resembled the one measured in the test. Engine emissions, which include $\mathrm{NO}_{x}, \mathrm{HC}, \mathrm{CO}$, and $\mathrm{CO}_{2}$, measured at various engine speeds and loads were compared to those predicted by the combustion simulations.

The modeling and testing evaluation of conventional diesel was chosen to provide a comparative baseline analysis that can be extended for predicting combustion emissions of renewable feedstock fuels in development.
\end{abstract}

\section{Key Words - conventional diesel, combustion, emissions modeling, emissions testing}

\section{1-INTRODUCTION}

Atmosphere pollution has become a global concern over the last two decades. Primary pollutants are those emitted directly to the atmosphere and secondary pollutants are formed by chemical or photochemical reactions of primary pollutants after they are admitted to the atmosphere and exposed to sunlight. Unburned hydrocarbons (HC), nitrogen oxides $\left(\mathrm{NO}_{\mathrm{x}}\right)$, sulfur oxides $\left(\mathrm{SO}_{\mathrm{x}}\right)$, and particulates are examples of primary pollutants. Peroxyacetyl nitrate (PAN) and ozone $\left(\mathrm{O}_{3}\right)$ are examples of secondary pollutants. The primary source of the $\mathrm{HC}$ and $\mathrm{NO}_{\mathrm{x}}$ has been readily identified to be the combustion exhaust from the internal combustion engine of automobile. Due to the enormous infrastructure investment, the internal combustion engine will likely remain the primary power source for transportation for decades. The need to preserve global environment by minimizing combustion pollution and maximizing combustion efficiency becomes increasing important each day.

Novel combustion with new engine technologies, fuel utilization with emerging fuel streams, and scientific understanding of fuel combustion have been identified as priority research directions [1]. In an attempt to achieve efficient and clean combustion, a number of new engine technologies, such as ultra- 
lean, high-pressure, and low-temperature diesel combustion have been promoted in evolving internal combustion engine designs. A combination of improved combustion technologies and exhaust aftertreatments can reduce the emissions from spark-ignited gasoline engines. However, emissions produced from the more efficient compression-ignited diesel engines at high compression ratios are more difficult to control [2].

Due to the rapid decline of crude oil reserves, research and development have been carried out to derive new fuels extracted from oil sands, oil shale, and renewable feedstock. These new fuels have physical and chemical properties that are quite different from those of the conventional petroleum fuels. Among the different fuel sources, diesel fuels derived from triglycerides, including vegetable oils and animal fats, present a promising alternative to substitute the traditional diesel fuels. Biodiesel fuel, fatty acid methyl ester, derived from triglycerides by transesterification with methanol has received most of the attention due to its renewability, improved exhaust emissions, and biodegradability [3].

To promote effective engine combustion by maximizing fuel energy output while minimizing unwanted emissions, it is vital to attain a predictive capability, which integrates experiment, theory, and modeling to facilitate realistic simulation of fuel combustion in engines. A grand challenge for $21^{\text {st }}$-century engine combustion science is to develop a validated, predictive, multiscale combustion modeling capability to optimize the design and operation of evolving fuels in advanced engines for transportation applications $[1,2]$. This predictive capability will enable a transition from hardware-intensive, experience-based fuel formulation and engine design to simulation-intensive, science-based design [1, 2].

The intent of this study is to use a predictive combustion simulation with direct-injection jet modeling to predict exhaust emissions from a four-stroke single cylinder diesel engine using conventional No. 2 diesel fuel. The predicted engine emissions, which include $\mathrm{NO}_{\mathrm{x}}, \mathrm{HC}, \mathrm{CO}$, and $\mathrm{CO}_{2}$, at various engine speeds

and loads are compared to those measured during engine emission tests. The modeling and testing evaluation of the conventional diesel has been chosen to provide a comparative baseline analysis that can be extended for predicting combustion emissions of renewable feedstock fuels in development. This research is not a solution to the grand challenge but is intended to be an accurate comparison of measured emissions with those modeled using a specific code.

\section{2-COMBUSTION EMISSIONS MODELING}

GT-Power software, developed by Gamma Technologies as a system level engine simulation tool, was used to perform engine combustion simulations. This software is based on one-dimensional gas dynamics and designed for steady-state and transient simulations to analyze flow and heat transfer in various components of an engine system. GT-Power has been used by other researchers to study combustion characteristics of cottonseed, linseed, and peanut oils in a heavy-duty direct-injection diesel engine [4] and to analyze performance and emissions of diesel and biodiesel fuels [5, 6].

In GT-Power, combustion refers to the transfer of a defined amount of fuel mass and air from an unburned zone to a burned zone in an engine cylinder, the release of chemical energy in the fuel-air mixture and the calculation of species and concentrations that result. During compression, combustion, and expansion processes in the cylinder, the combustion rate is controlled by the burn rate, the rate at 
which fuel and air molecules are transferred to the burned zone from the unburned zone and begin to participate in the chemical reactions.

A predictive combustion simulation, Direct-Injection Jet (DIJet) modeling [7], has been used in this research to predict burn rate and combustion emissions. The total injected fuel mass is divided into five radial zones and a certain number of axial zones. At each time step during the fuel injection period, an axial slice with five radial zones is injected into the engine cylinder. The DIJet model only analyzes the fuel plume from one nozzle hole. The fuel mass in each axial slice is determined by the fuel injection pressure at that time step and the elapsed time since the last zones were injected. The injected fuel mass in each time step is divided equally among the five radial zones.

Each zone contains subzones for liquid fuel, unburned vapor fuel and entrained air, and burned gases. As the liquid fuel is injected into the cylinder, the fuel entrains air and begins to evaporate, thus forming the unburned subzone. The outer zones entrain air more quickly than the inner zones, thus decreasing their velocity more quickly due to momentum conservation and resulting in less penetration distance as can be seen in figure 1.
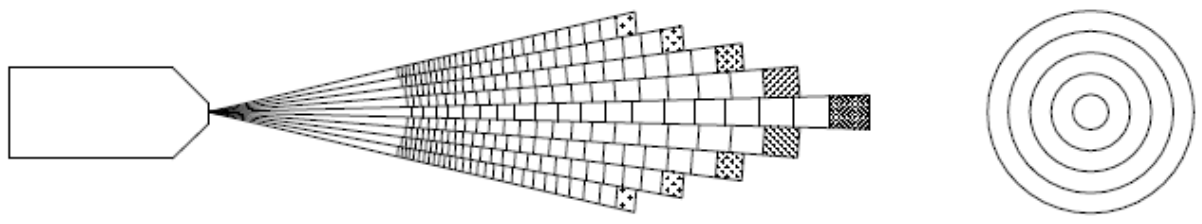

Figure 1. Fuel jet breakup into radial and axial zones in a DIJet model [7]

The zonal temperature is calculated by the injected fuel temperature, entrained air temperature, and the effect of fuel evaporation. The zonal fuel-to-air ratio is determined by the vapor fuel mass and entrained air mass in each unburned subzone. When the combination of cylinder pressure, zonal temperature, and fuel-to-air ratio becomes combustible, the fuel in the unburned subzone ignites and results in changes of temperature and composition. All combustion products are then moved to the burned subzone.

The DIJet model predicts the combustion burn rate by predicting the evaporation rate of droplets that have broken from the injected stream of fuel and the entrainment of air by the fuel jet. To accurately predict the fuel jet velocity as a function of time, the DIJet model requires an accurate input of fuel injection pressure profile as a function of crank angle. The burn rate predicted by the DIJet model is extremely sensitive to the fuel injection profile and timing.

The fuel injection pressure profile, pressure versus crank angle, required by the GT-Power DIJet model is the pressure profile in the injector sac which is a small volume inside the injector between the plunger and the spray nozzles. Figure 2 shows a typical fuel injection nozzle of a diesel engine [8]. The fuel injector sac pressure is difficult to measure due to difficult accessibility, very high pressure, and high frequency 
response required. With the fuel pump system that the test engine uses, two absolute pressure transducers in a pressure range of approximately 2000 bar were used to measure fuel pressures at two different points, fuel pump end and nozzle holder end, along the injection line. The pressure and velocity in the injector sac area were computationally determined by the pressures measured at these two points. A schematic illustration for determining the fuel injector sac pressure profile is shown in figure 3. The fuel pressure varies along the fuel injection line; however, the fuel pressure in the nozzle chamber and sac chamber is considered to be uniform.

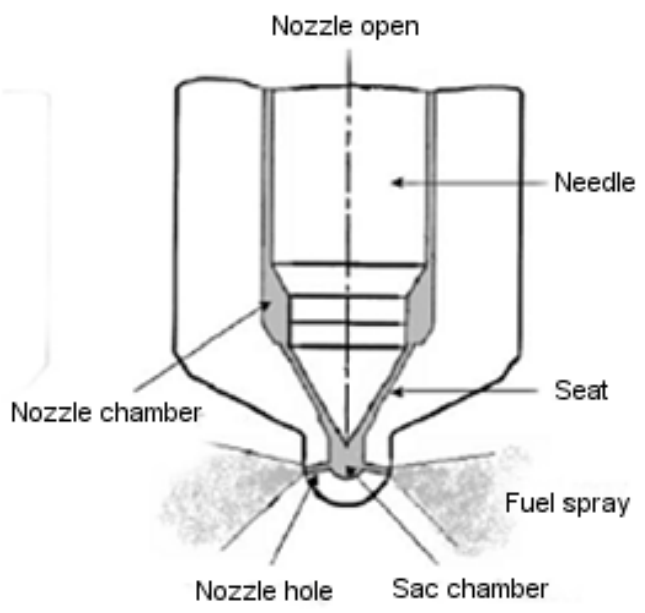

Figure 2. Illustration of a fuel injection nozzle of a diesel engine [8]

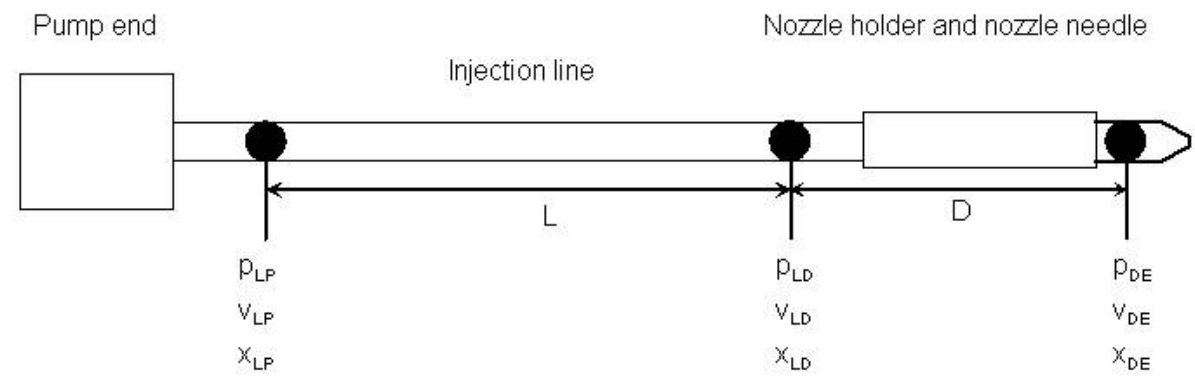

Figure 3. Fuel injector sac pressure measurement

The amount of engine intake air flow has a significant influence on the engine performance and emissions. In GT-Power modeling, users are required to input flow arrays of "discharge coefficient” versus "valve lift" for both intake and exhaust valves. The discharge coefficient is defined as the ratio of the effective flow area to a reference flow area when the air flow passes through a flow restriction. For an engine cylinder, the reference flow area can be the valve seat area for the intake or exhaust valve. 
Due to the friction, surface tension, and other non-ideal flow effects, only part of the reference flow area is used to carry the flow. Therefore, the value of a discharge coefficient is always less than unity. In some references, the discharge coefficient is defined as the ratio of actual mass flow rate to theoretical mass flow rate. The discharge coefficients are typically determined by experiments.

To perform the described air flow measurements, typically the engine cylinder heads need to be removed and mounted onto a flow bench. The intake and exhaust valve lifts are adjusted by micrometer valve adjustors. For a given valve opening, a pressure differential is introduced across the valve to induce air flow. To calculate the air flow discharge coefficient at a given lift-to-diameter ratio of either the intake or exhaust valve, it is required to know the air pressure drop and flow rate across the valve. A GT-Power simulation requires air flow array inputs of forward and reverse discharge coefficients for both the intake and exhaust valves. "Forward” and "reverse” mean opposite flow directions across the valves.

To have meaningful comparisons between analytically predicted and experimentally measured combustion emissions, the engine inputs to the GT-Power models need to be as accurate as possible. Ismail [9] et al. conducted airflow experiments using a flow bench to measure the discharge coefficients of intake and exhaust valves for a direct injection diesel engine. The flow discharge coefficients reported in [9] were modified in this study by the test engine valve dimensions; the modified discharge coefficients have been used in the GT-Power combustion simulations.

\section{3-COMBUSTION EMISSIONS TESTING}

A four-stroke single cylinder direct injection diesel engine was used for No. 2 diesel fuel emissions testing in this research. The purpose of the testing is to compare actual measured emissions to combustion simulation results. The test engine specifications are listed in table 1 . The measured intake and exhaust valve lift curves are shown in figure 4, in which the zero-degree and 180-degree crank angles are the top dead center (TDC) and bottom dead center (BDC), respectively.

Table 1. Specifications of diesel engine used in emissions testing

\begin{tabular}{|l|l|}
\hline Engine Type & $\begin{array}{l}\text { Single-Cylinder, 4-Cycle, Air-Cooled } \\
\text { Diesel Engine }\end{array}$ \\
\hline Combustion System & Direct Injection System \\
\hline Bore & $86 \mathrm{~mm}$ \\
\hline Stroke & $70 \mathrm{~mm}$ \\
\hline Displacement Volume & $406 \mathrm{~cm}^{3}$ \\
\hline Continuous Output & $6.6 \mathrm{~kW}$ \\
\hline Rated Speed & $3600 \mathrm{RPM}$ \\
\hline Compression Ratio & 19.3 \\
\hline Fuel Injection Pressure & $196 \mathrm{bar}$ \\
\hline
\end{tabular}




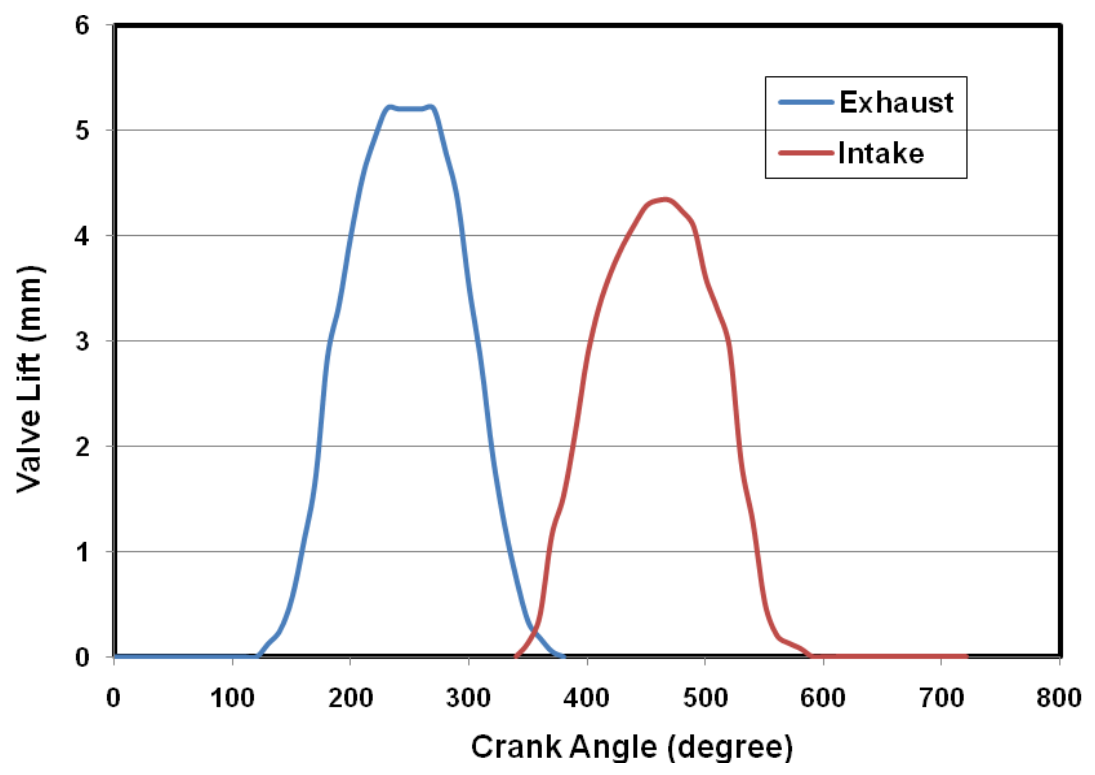

Figure 4. Measured valve lift curves of diesel engine used in emissions testing

In each emissions test, cylinder pressure versus crank angle was measured and used to calibrate the predicted cylinder pressure profile so that correct burn rate could be used for emissions predictions. To add a pressure port to the test engine for in-cylinder pressure measurement, a hole needs to be drilled into the engine in such a way that does not damage the cylinder's integrity or breach the water jacket or oil passages. A bore of $4.95 \mathrm{~mm}$ in diameter and $10.2 \mathrm{~mm}$ in length was drilled into the cylinder head and threaded to hold a Kistler high-temperature pressure transducer. From that depth, a counter bore of $1 \mathrm{~mm}$ diameter was drilled further into the cylinder head and another bore of the same diameter as the counter bore was drilled from the combustion chamber surface of the head to meet the counter bore at a right angle, thereby forming a direct passage into the cylinder volume that enables the pressure sensor to detect pressure changes in the cylinder as the piston moves. This was done with as much precision as possible so as to minimally affect the volume of the cylinder, and thus the pressure, when the engine is running. The pressure sensor was connected using a BNC connector to the charge amplifier, which was in turn wired to an analog channel on a National Instruments CompactRio programmable automation controller.

A Hall Effect sensor senses the teeth on the crank wheel connected to the crankshaft. The wheel has 36 teeth and each tooth denotes 10 degree of crank rotation. The sensor was supplied with $12 \mathrm{~V}$ from a DC power supply and its output signal (in volts) was fed into the CompactRio for scaling and manipulation. The working principle of the Hall Effect sensor and the characteristics of its signal were studied to come up with a calibration and a code that converted the square wave signal corresponding to each tooth into crank angle in degrees with a revolution marker to verify every 360 degrees turned and the positions of the TDC and BDC.

The CompactRio device was configured and programmed to read outputs from the pressure sensor and the Hall Effect sensor. Data scaling and manipulation were carried out to give final output data in appropriate engineering units. While the pressure sensor was used to measure pressure variation in the 
cylinder, the Hall Effect sensor was used to determine crank angle, engine speed, and the position of the piston with respect to the TDC and BDC. The final data were correlated and plotted to generate an incylinder pressure profile at a given engine speed-load combination.

The diesel engine exhaust emissions were measured by a $\mathrm{NO}_{\mathrm{x}}$ sensor connected to a MEXA 720- $\mathrm{NO}_{\mathrm{x}}$ emissions analyzer and a $\mathrm{HC} / \mathrm{CO} / \mathrm{CO}_{2}$ sensor connected to a MEXA 554-JU emissions analyzer. These emissions sensors were fully calibrated prior to the testing. A schematic diagram of the experimental setup is shown in figure 5 .

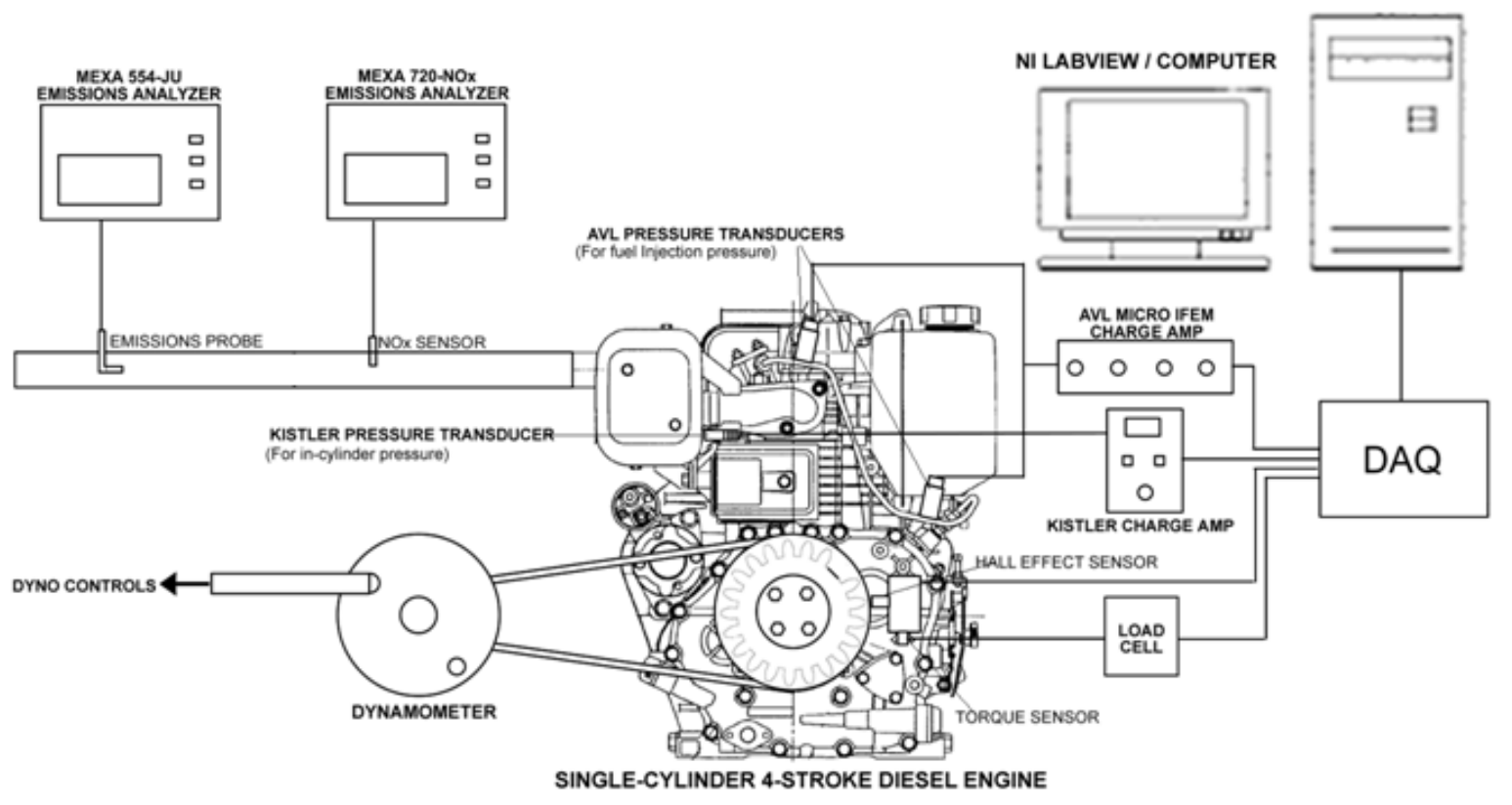

Figure 5. Schematic diagram of experimental setup

The fuel injector sac pressure profile, which includes fuel pressure magnitude and duration, is a critical input to the DIJet combustion model. Two AVL high-pressure transducers (SL31D-2000) with a measuring range of 0 to 2000 bar, a microIFEM Combi Module 4C3x charge amplifier, and AVL data acquisition system analysis software of IndiSignal and Concerto were used to measure the fuel injector sac pressure profile.

Allievi equations, comprehensively described in technical literature, can be used to link the velocity and pressure of the fuel at two separated points along the fuel injection line. As shown in figure 3, if the timebased pressure curves of $\mathrm{P}_{\mathrm{LP}}$ at the pump end and $\mathrm{P}_{\mathrm{LD}}$ at the nozzle holder end are known, the fuel velocity curves of $V_{L P}$ and $V_{L D}$ can be determined by using the Allievi equations. The calculated fuel velocity curve of $\mathrm{V}_{\mathrm{LD}}$ and the measured fuel pressure curve of $\mathrm{P}_{\mathrm{LD}}$ at the nozzle holder end can then be used to calculate the fuel pressure curve of $P_{D E}$ at the entry into the nozzle chamber by using the Allievi equations again. The fuel pressure in the nozzle chamber and sac chamber is considered to be uniform. 
The nozzle chamber fuel pressure curve of $\mathrm{P}_{\mathrm{DE}}$ is required for the calculation of nozzle needle lift, which is modeled as a mechanical spring/mass/damper system with a degree of freedom. The nozzle needle lift determines the start and end of fuel injection as well as the open nozzle hole area. The fuel injection rate is calculated from this information.

The AVL pressure sensors were installed at the ends of the injection line, one at the fuel pump end and the other at the nozzle holder end, using solder-on adaptors. Two 1-mm diameter holes were drilled into the injection line at the installation locations and aligned with the holes in the adaptors before brazing them to the injection line. The pressure sensors were screwed into the adaptors (tightening torque $=15$ $\mathrm{Nm}$ ), thereby creating a 1-mm channel connecting the sensor directly with the fuel flow through the adaptor and the injection line.

The microIFEM Combi Module 4C3x system houses two independent Piezo amplifiers (CG1 and CG2) and two independent MP amplifiers (VG1 and VG2) with different uses. For the current application, strain gauge pressure measurements, that require a precise stable power supply and high gain factor, are desired and the MP amplifiers are suitable for this purpose.

Before connecting both pressure sensors to the VG1 and VG2 channels, the microIFEM was powered on and connected to the serial port on the computer and the IndiSignal application was started. IndiSignal was used to parameterize the amplifier. It displayed all four amplifiers in the microIFEM system and properties required for the relevant amplifiers in use were set.

IndiSignal calculated a Signal Calibration Factor (SCF) for both pressure sensors. This factor is used to convert the output signal from the microIFEM (volts) to pressure in whatever pressure unit is specified by the user in IndiSignal (bar in this case). The sensors were connected to the VG1 and VG2 channels respectively based on the channel calibration in IndiSignal. The clamp-on ferrites were installed close to the amplifier end of the sensor cables to reduce noise in the signals. Two BNC cables connected the output from the microIFEM to the DAQ system with two low-pass signal filters installed between the BNC cables and the DAQ system to further attenuate noise in the signals into the DAQ.

Before fuel pressure measurements were taken, the pressure signals were zeroed by disconnecting one end of the injection line, thereby subjecting the transducers to the barometric pressure in the laboratory. The "Bridge Offset" property was adjusted until both transducers read the barometric pressure at zero gage pressure. Next, the injection line was re-connected and the National Instruments Labview application was started. Finally, the engine was started and the sampling rate was set at $120 \mathrm{kHz}$ with a total of 100,000 data points logged for each engine speed-torque combination. Data logged include engine speed, torque from the dynamometer controls, pressure pulses from both pressure sensors, and crank angle position using signal from the Hall Effect sensor.

AVL's Concerto application was used to analyze the measured data to give the required parameters. The crank-angle based pressure profiles were saved into a spreadsheet in the form of ".csv" (comma-separated values) files. The file was then imported into Concerto for post-processing. In Concerto, a Graphical Formula Editor (CalcGraf) was used to model the fuel injection system by using the "InjectionRate" 
macro. This function took the time-based pressure profiles measured at the fuel pump end and nozzle holder end as inputs and calculated nozzle needle lift, injection rate, sac fuel velocity, sac pressure and start of injection.

The processing of pressure inputs was done with a detailed knowledge of the dimensions and properties of the injector nozzle. Due to lack of availability of information from the original engine manufacturer, a spare injector nozzle was obtained and dissected to reveal the internal parts, whose dimensions were subsequently measured. To find the fuel injector nozzle internal component details required by the "InjectionRate" macro, a high-precision vernier caliper was used to measure the length dimensions, an optical comparator was used to measure the angular dimensions, and a scale was used to measure the mass. These values were entered into a file called "inj_one.jpa” which was in turn entered into the macro as a parameter. Other parameters required by the macro included engine speed, distance from the sac to the nozzle holder end of the line, calculation range (in crank angle degrees), and calculation resolution (in crank angle degrees). Some of the required dimensions in the fuel injector nozzle are shown in figures 6 and 7.

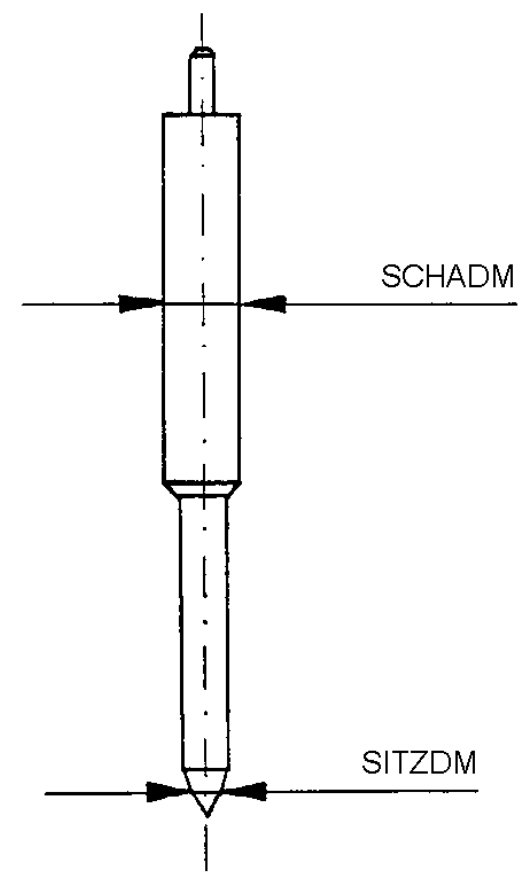

Figure 6: Fuel injector nozzle holder and needle dimensions required by CalcGraf 


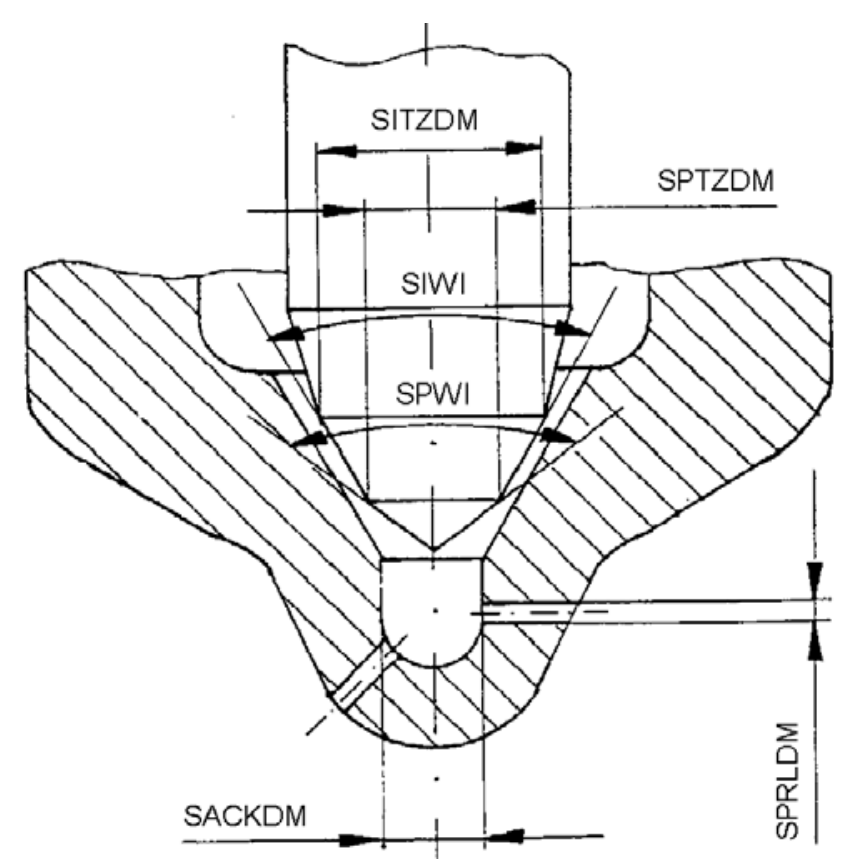

Figure 7: Close-up of fuel injector nozzle tip and internal dimensions required by CalcGraf

\section{4-RESULTS AND DISCUSSION}

Combustion emissions tests using No. 2 diesel fuel were conducted at two engine speeds of 2200 and 2600 RPM. Four different loads of 2.5, 5, 7.5, and10 Nm were applied to the test engine at each speed. The measured in-cylinder pressure profiles and fuel injector sac pressure profiles of these emissions tests are shown in figures 8, 9, 10 and 11. The in-cylinder pressure profiles, shown in figures 8 and 10, are smooth as expected, which indicates the combustion process in the cylinder is normal. However, the measured sac pressure profiles, displayed in figures 9 and 11, show some oscillations. It can be suggested that while the nozzle is supposed to inject fuel once, the fuel injector sac pressure profiles show that smaller injection events took place rapidly after the first injection, thus resulting in the pressure fluctuations noticed in the sac pressure profiles.

The fuel injector sac pressure profiles shown in figures 9 and 11 were used as modeling inputs in the GTPower combustion simulations. Fuel injection quantities per cycle required in the GT-Power simulations were determined by performing numerical integrations on the Concerto-measured fuel injection rate profiles. The simulation-predicted cylinder pressure profiles are compared with those measured in the emissions tests at various engine speeds and engine loads. Figures 12 to 19 show the in-cylinder pressure comparison for the No. 2 diesel fuel between simulation predictions and test measurements at engine speeds of 2200 and 2600 RPM under engine loads of 2.5, 5, 7.5, and10 Nm. As shown in figures 12 to 19 , the predicted and measured cylinder pressure profiles agree very well for all the emissions simulations performed and tests conducted. 


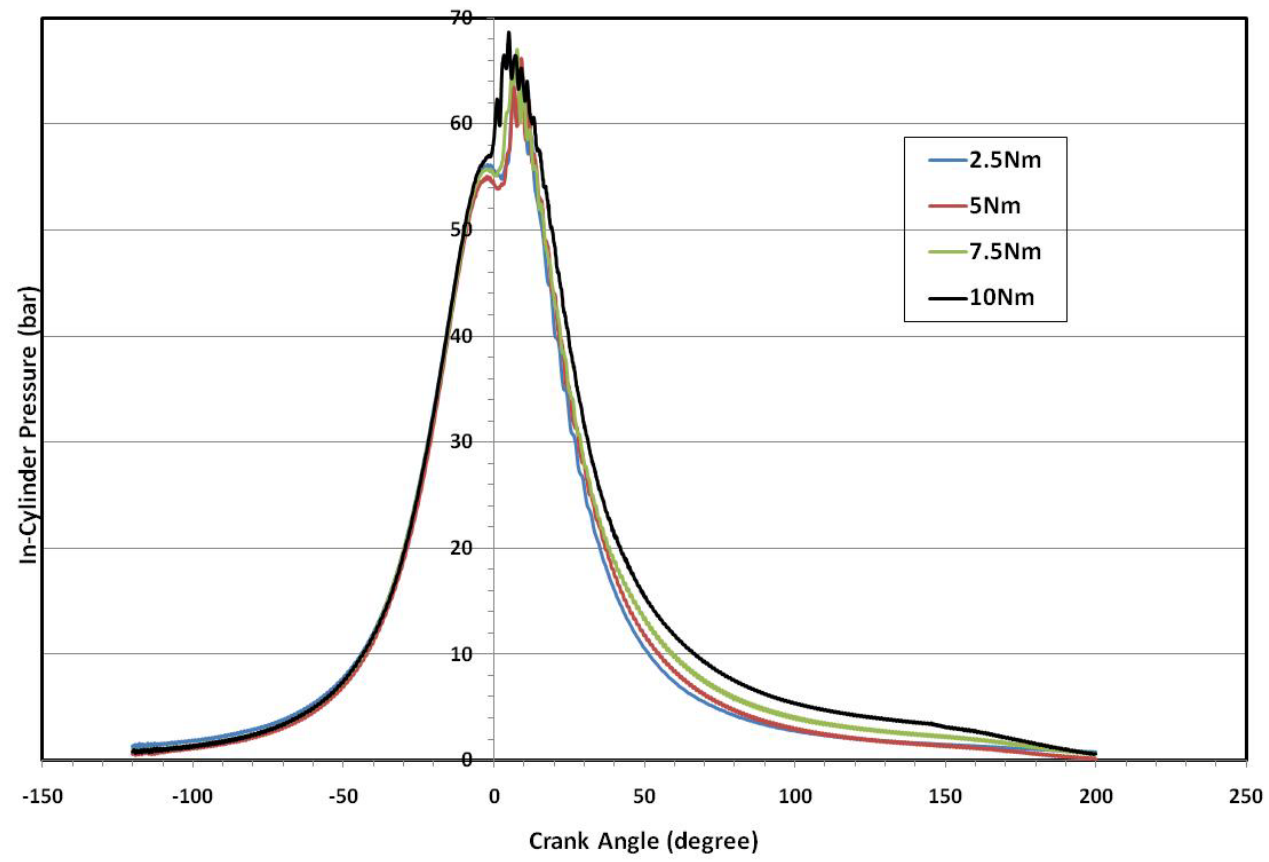

Figure 8. Measured in-cylinder pressure profiles at engine speed of 2200 RPM under engine loads of 2.5/5/7.5/10 Nm (No. 2 diesel fuel)

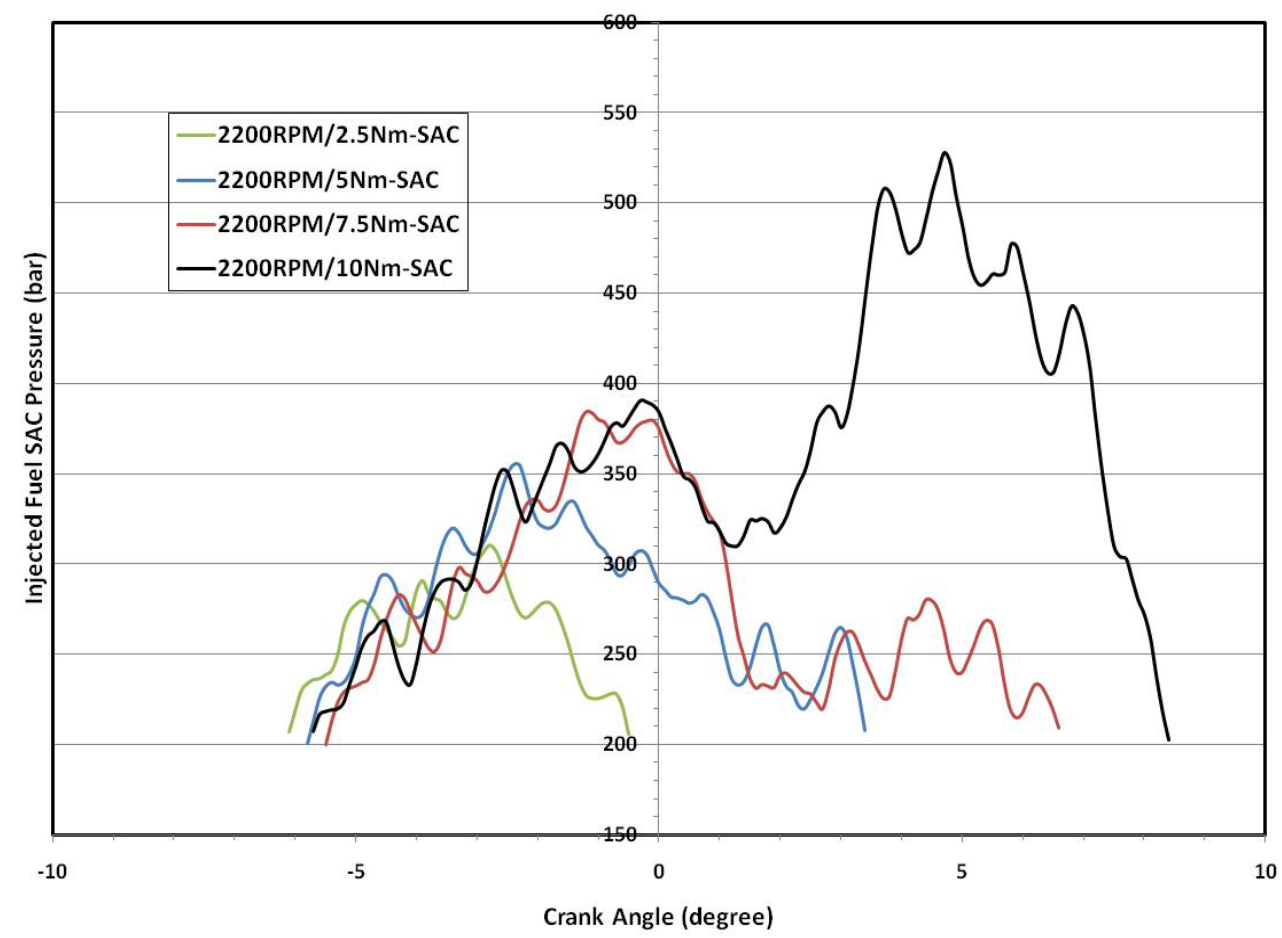

Figure 9. Measured fuel injector sac pressure profiles at engine speed of 2200 RPM under engine loads of 2.5/5/7.5/10 Nm (No. 2 diesel fuel) 


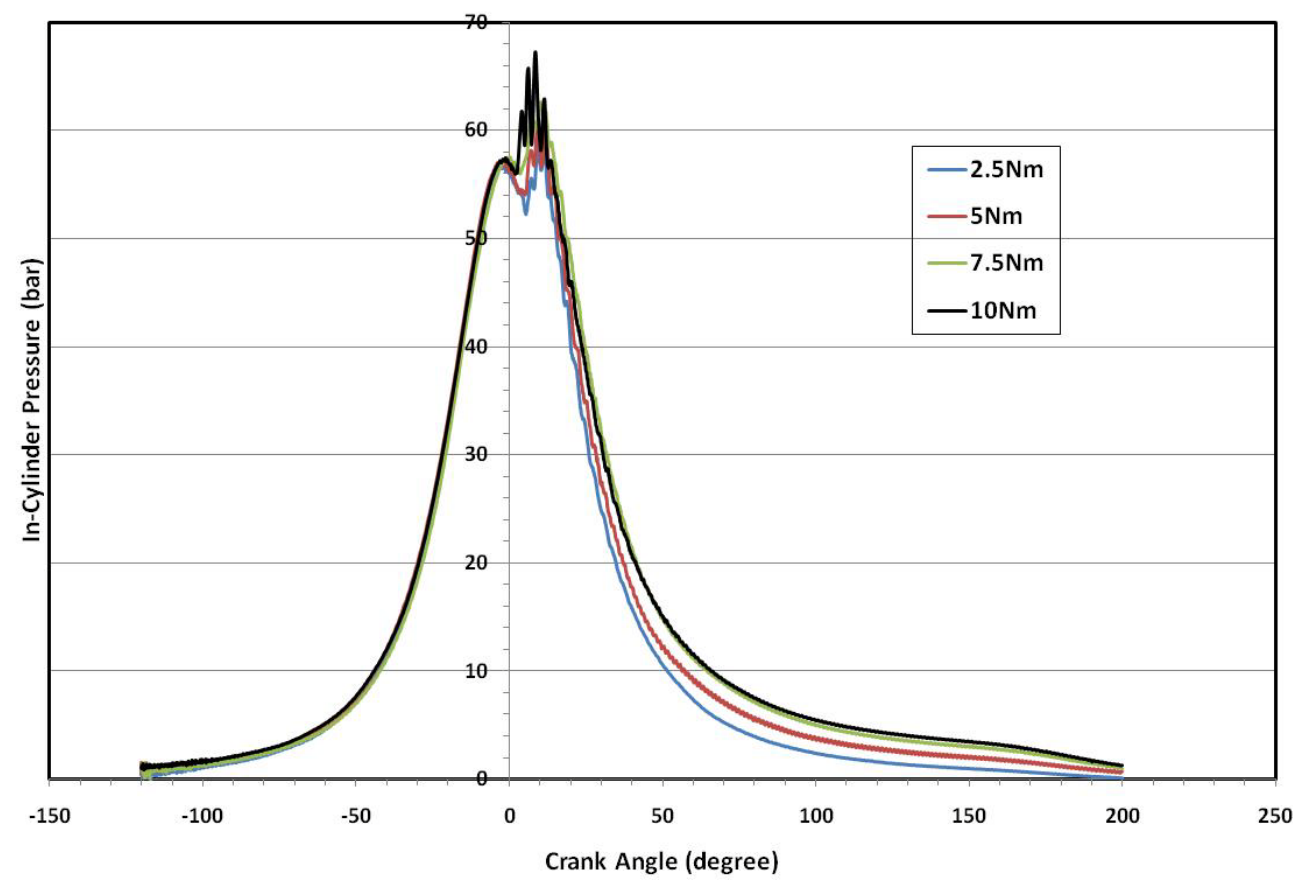

Figure 10. Measured in-cylinder pressure profiles at engine speed of 2600 RPM under engine loads of 2.5/5/7.5/10 Nm (No. 2 diesel fuel)



Figure 11. Measured fuel injector sac pressure profiles at engine speed of 2600 RPM under engine loads of 2.5/5/7.5/10 Nm (No. 2 diesel fuel) 




Figure 12. Predicted and measured in-cylinder pressure profiles at engine speed of 2200 RPM and engine load of $2.5 \mathrm{Nm}$ (No. 2 diesel fuel)

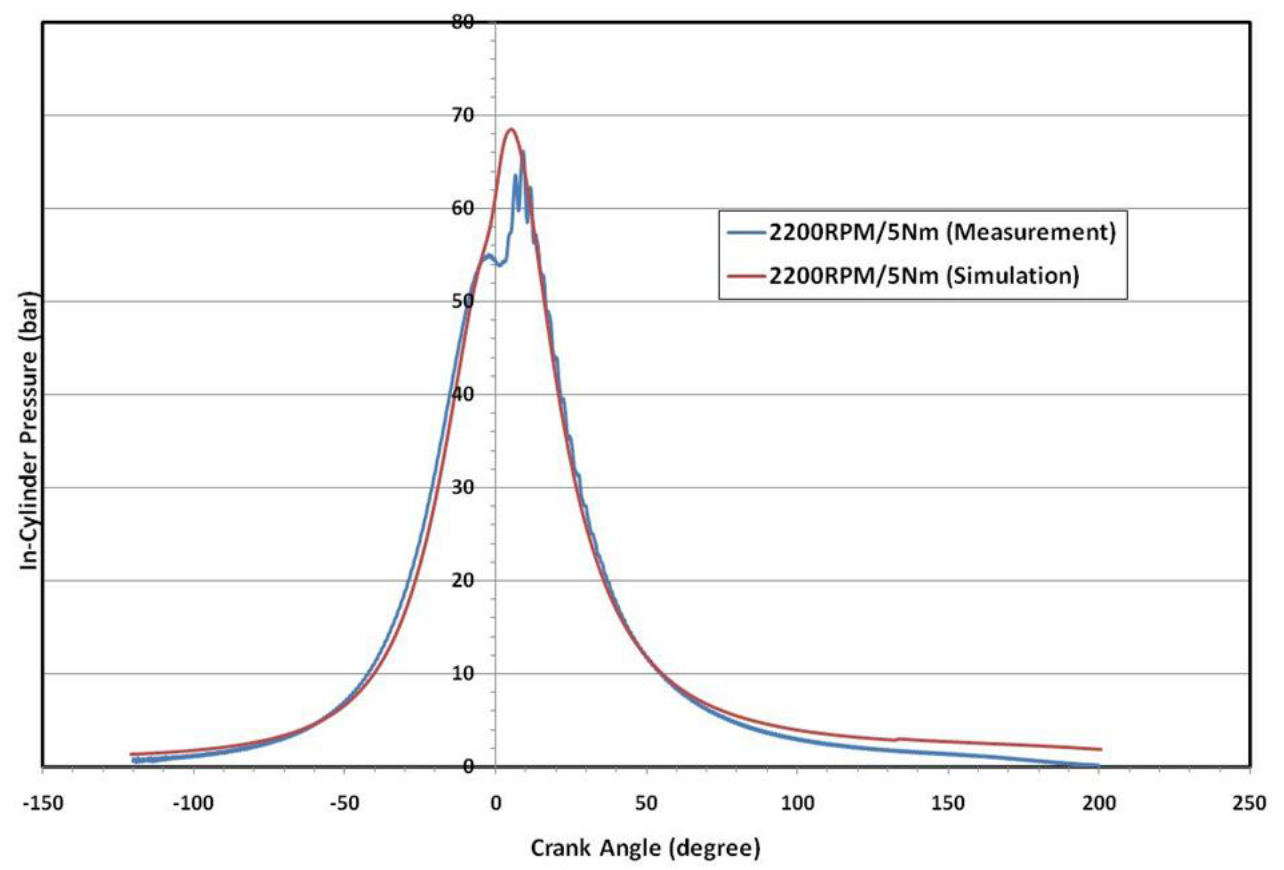

Figure 13. Predicted and measured in-cylinder pressure profiles at engine speed of 2200 RPM and engine load of $5 \mathrm{Nm}$ (No. 2 diesel fuel) 




Figure 14. Predicted and measured in-cylinder pressure profiles at engine speed of 2200 RPM and engine load of 7.5 Nm (No. 2 diesel fuel)

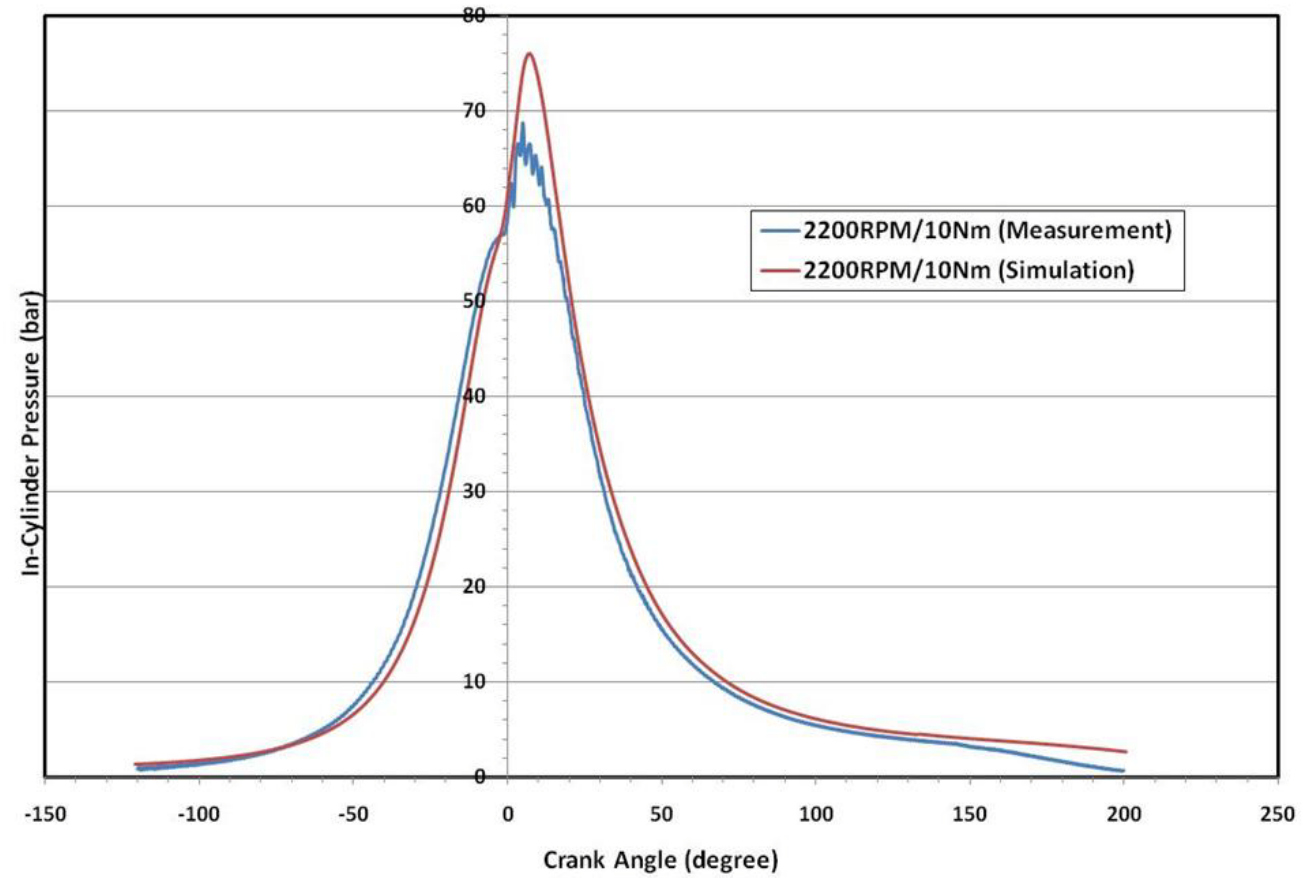

Figure 15. Predicted and measured in-cylinder pressure profiles at engine speed of 2200 RPM and engine load of $10 \mathrm{Nm}$ (No. 2 diesel fuel) 


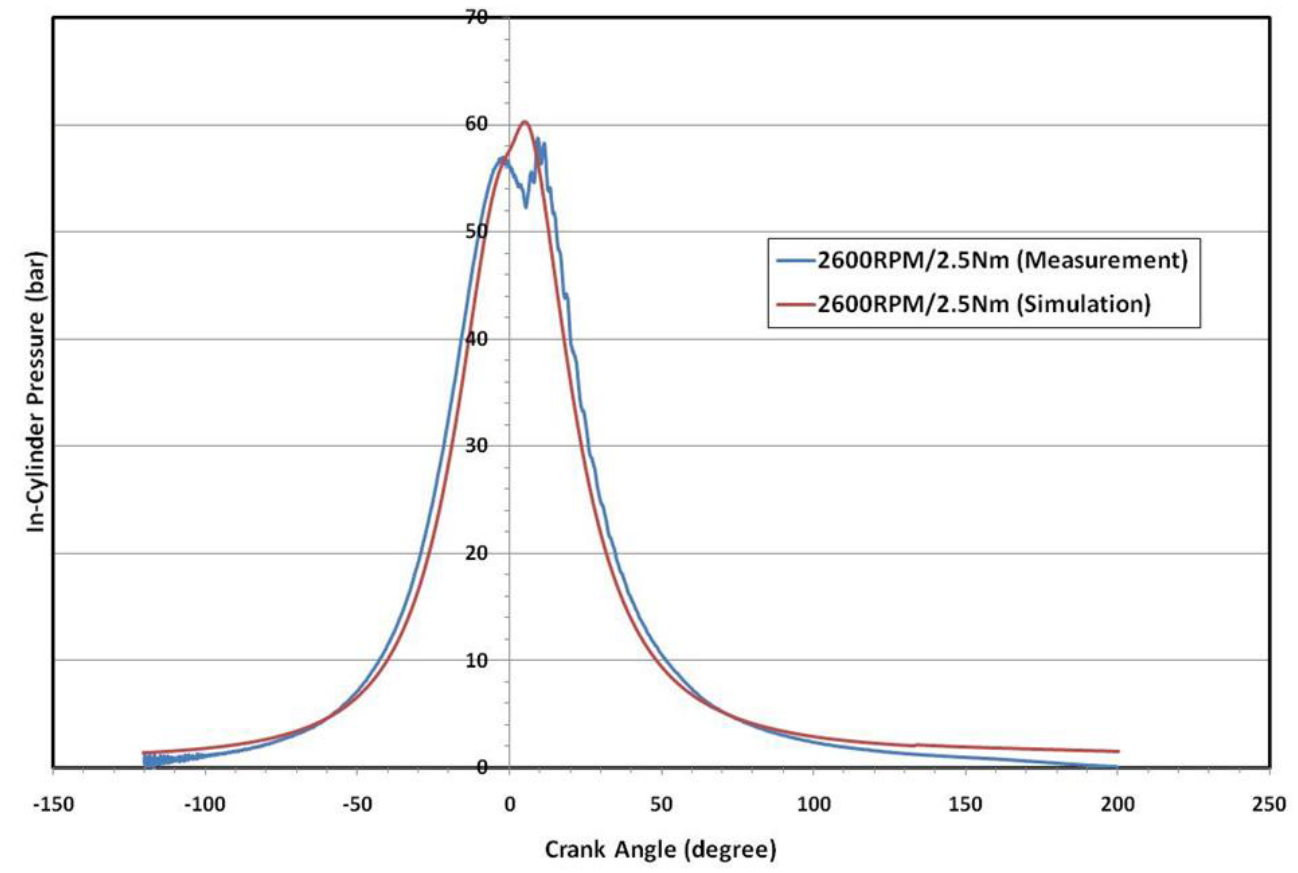

Figure 16. Predicted and measured in-cylinder pressure profiles at engine speed of 2600 RPM and engine load of $2.5 \mathrm{Nm}$ (No. 2 diesel fuel)

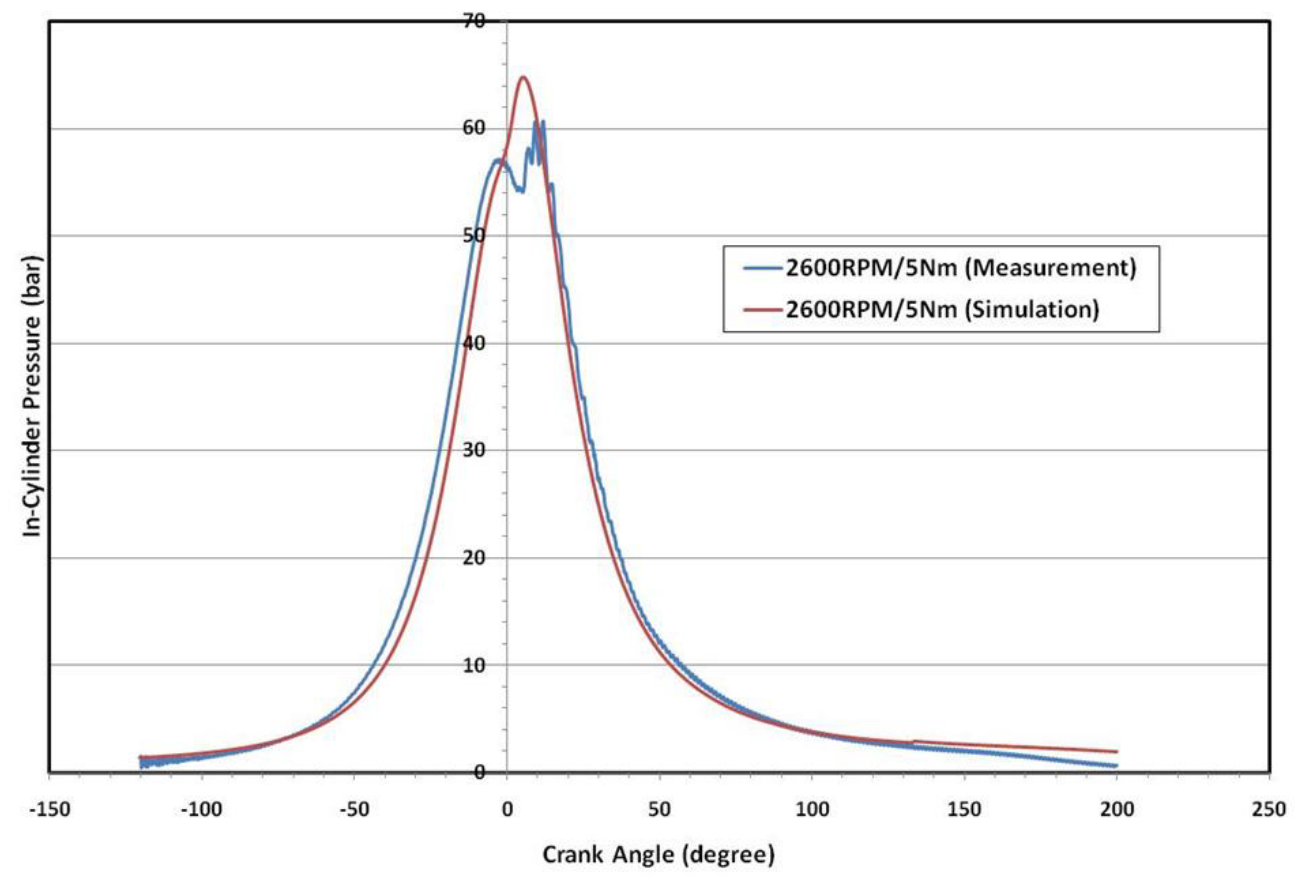

Figure 17. Predicted and measured in-cylinder pressure profiles at engine speed of 2600 RPM and engine load of $5 \mathrm{Nm}$ (No. 2 diesel fuel) 


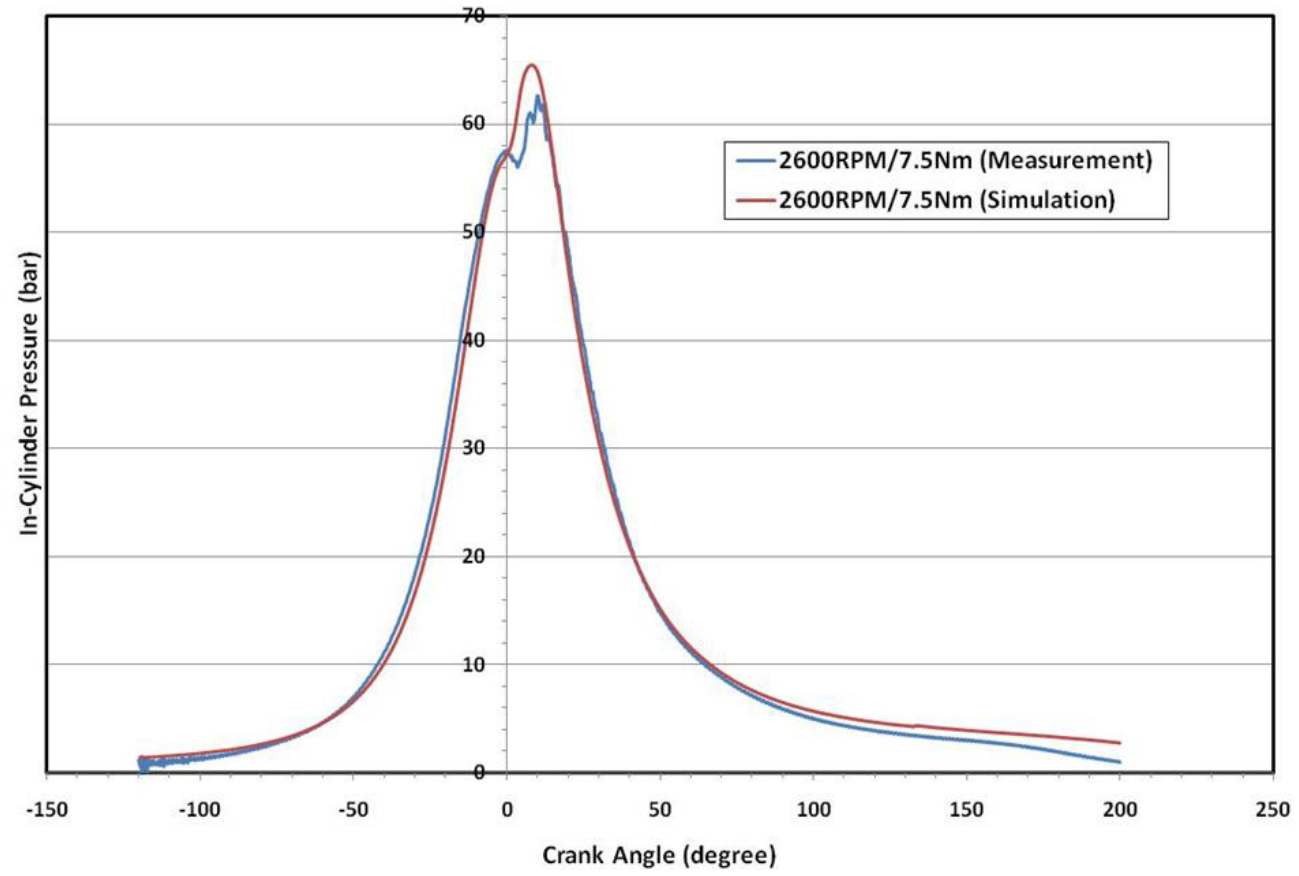

Figure 18. Predicted and measured in-cylinder pressure profiles at engine speed of 2600 RPM and engine load of 7.5 Nm (No. 2 diesel fuel)



Figure 19. Predicted and measured in-cylinder pressure profiles at engine speed of 2600 RPM and engine load of $10 \mathrm{Nm}$ (No. 2 diesel fuel) 
The GT-Power simulations also predicted some combustion parameters that were difficult to be measured in the emissions tests, such as cylinder temperature and heat release rate profiles. Figures 20 to 25 show the simulation-predicted profiles of cylinder temperature, apparent heat release rate, and $\mathrm{NO}_{\mathrm{x}}$ concentration, resulted from No. 2 diesel combustion in the test engine at the described engine speeds and loads. As expected, at a given engine speed, the cylinder pressure increases with increasing engine load and the cylinder temperature also increases with increasing engine load.

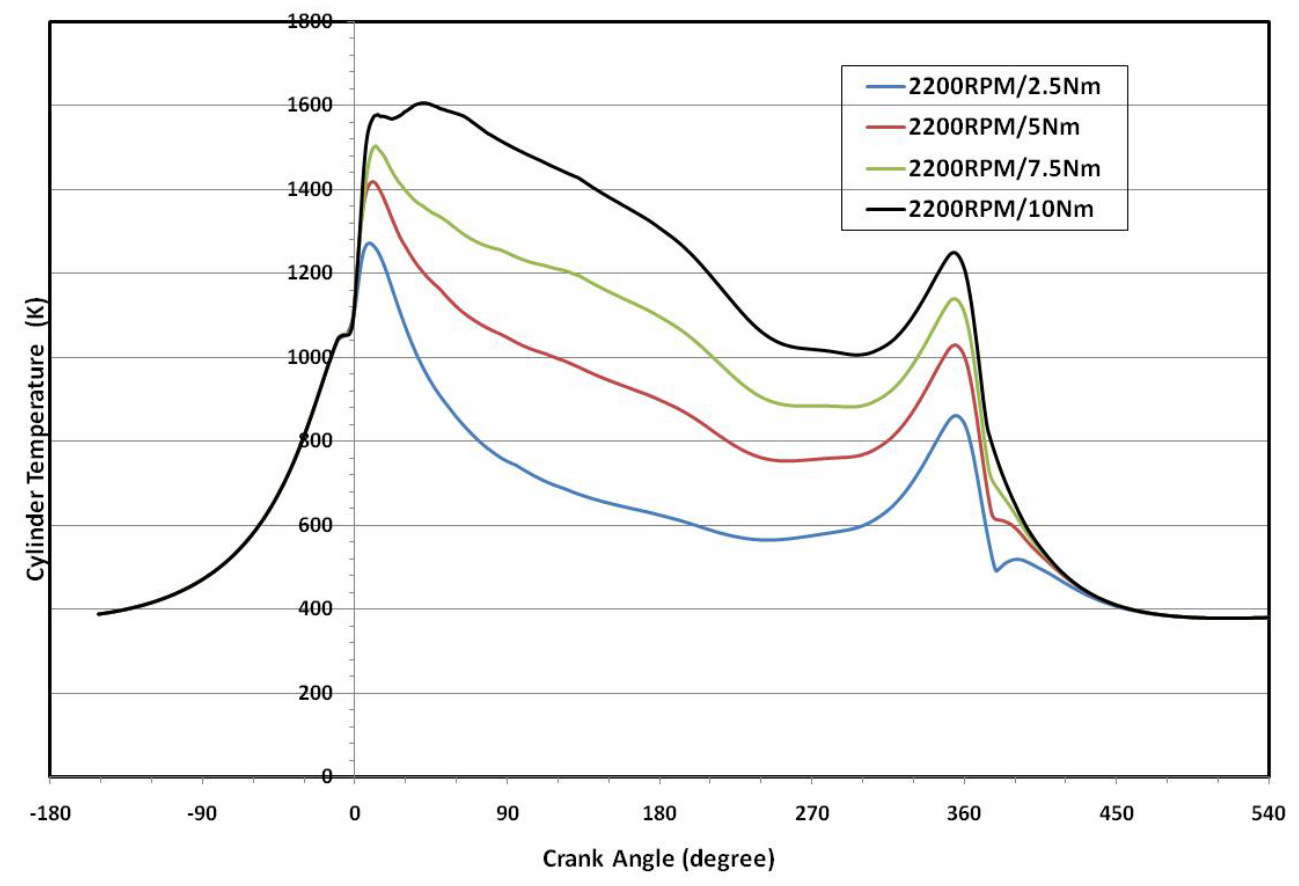

Figure 20. Simulation-predicted cylinder temperature at engine speed of 2200 RPM and engine loads of 2.5/5/7.5/10 Nm (No. 2 diesel fuel) 


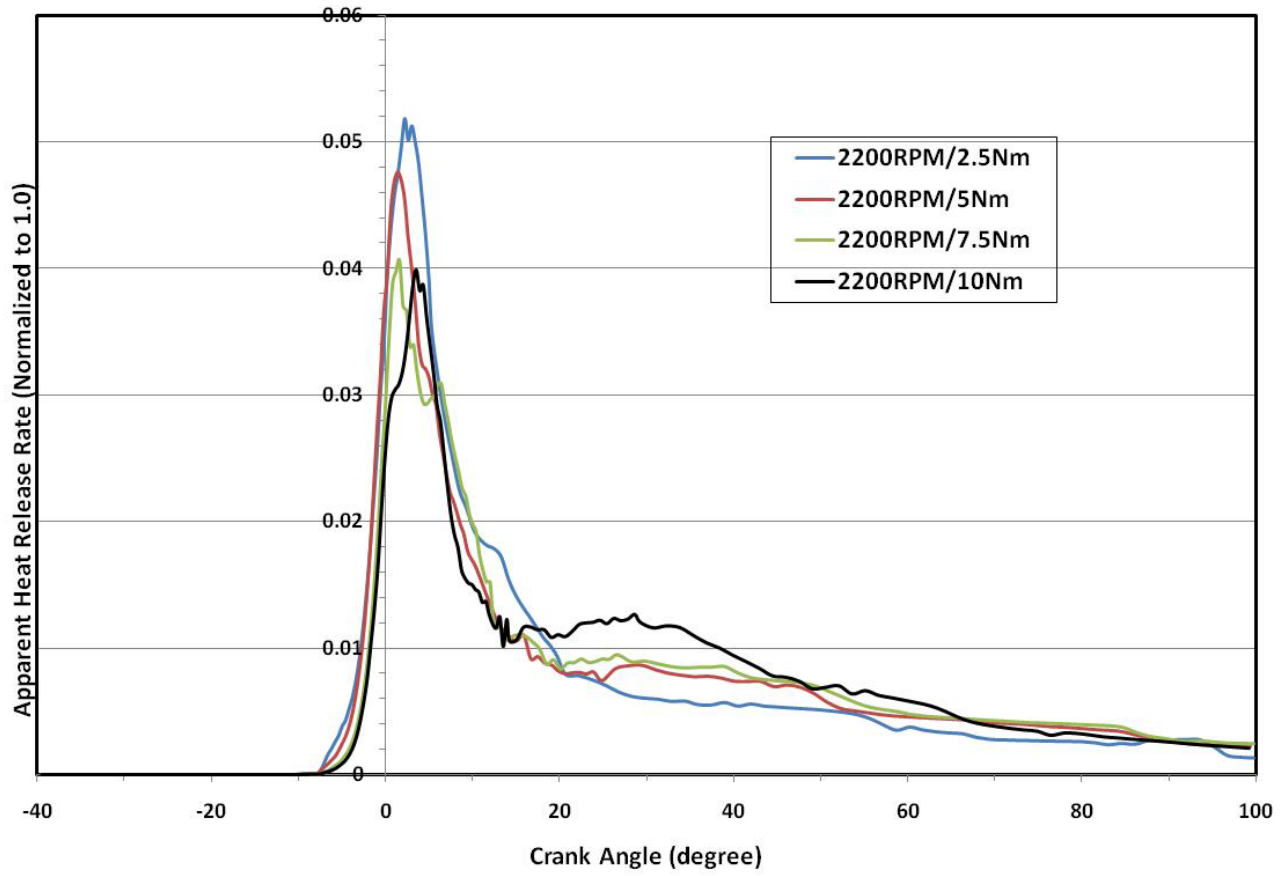

Figure 21. Simulation-predicted apparent heat release rate at engine speed of $2200 \mathrm{RPM}$ and engine loads of 2.5/5/7.5/10 Nm (No. 2 diesel fuel)



Figure 22. Simulation-predicted $\mathrm{NO}_{\mathrm{x}}$ concentration at engine speed of $2200 \mathrm{RPM}$ and engine loads of 2.5/5/7.5/10 Nm (No. 2 diesel fuel) 


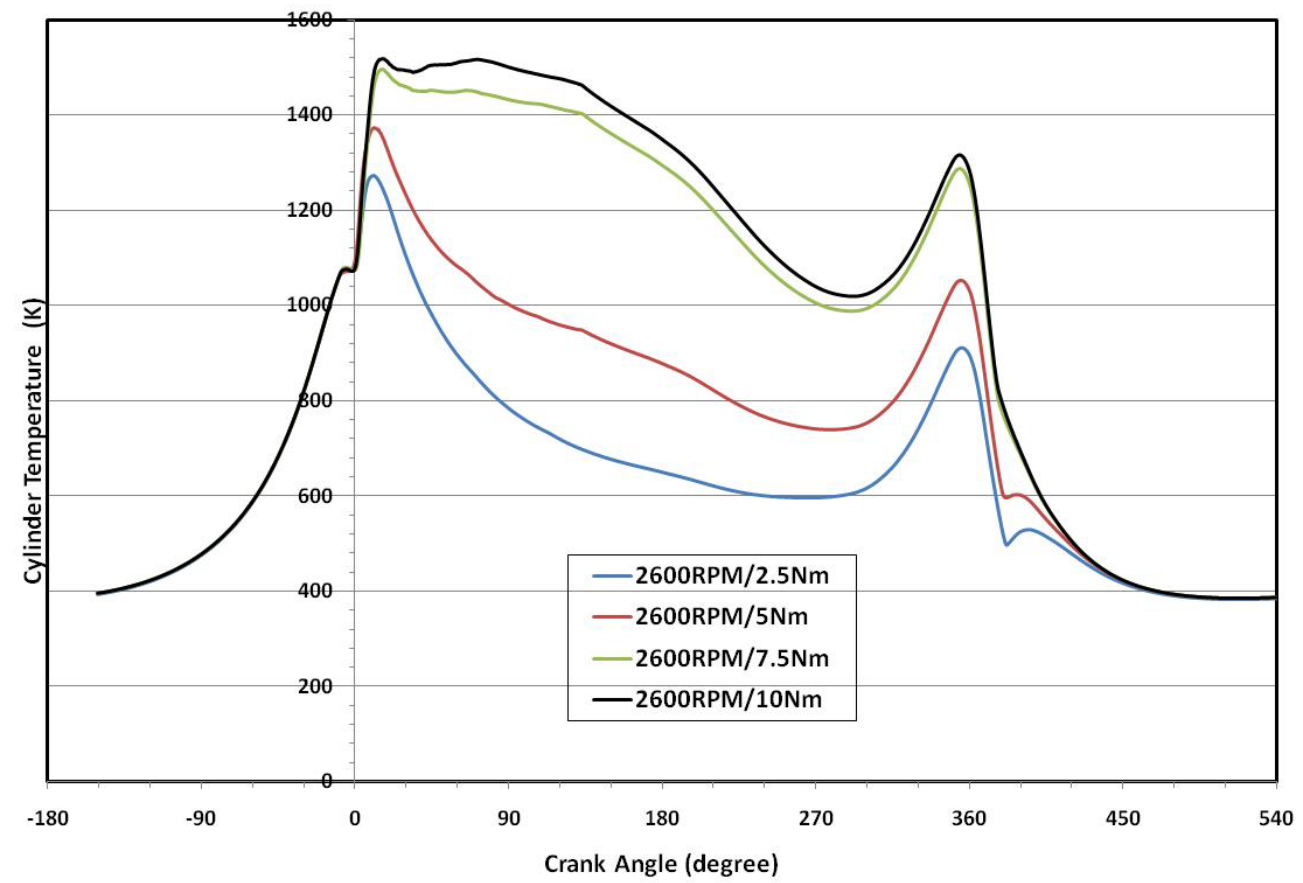

Figure 23. Simulation-predicted cylinder temperature at engine speed of 2600 RPM and engine loads of 2.5/5/7.5/10 Nm (No. 2 diesel fuel)

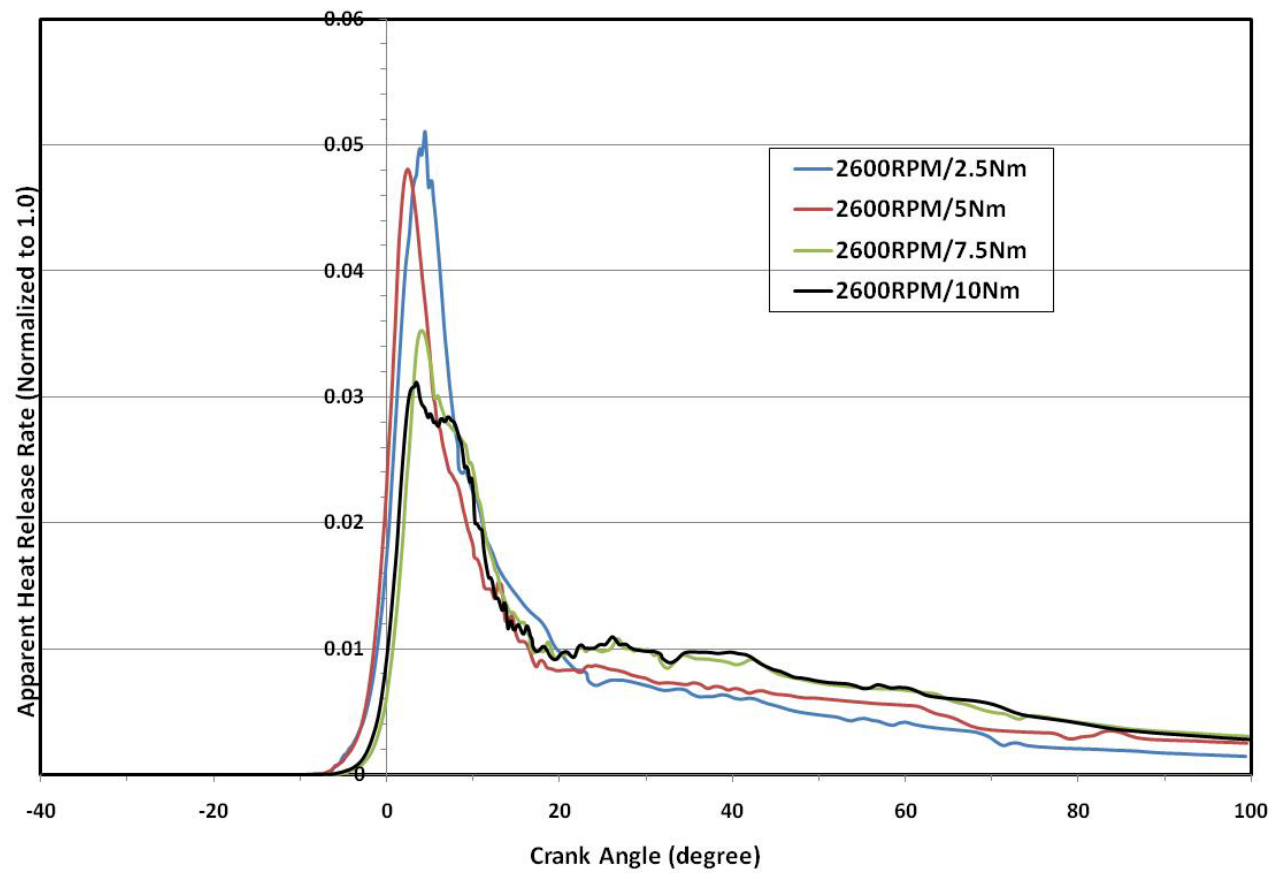

Figure 24. Simulation-predicted apparent heat release rate at engine speed of 2600 RPM and engine loads of 2.5/5/7.5/10 Nm (No. 2 diesel fuel) 


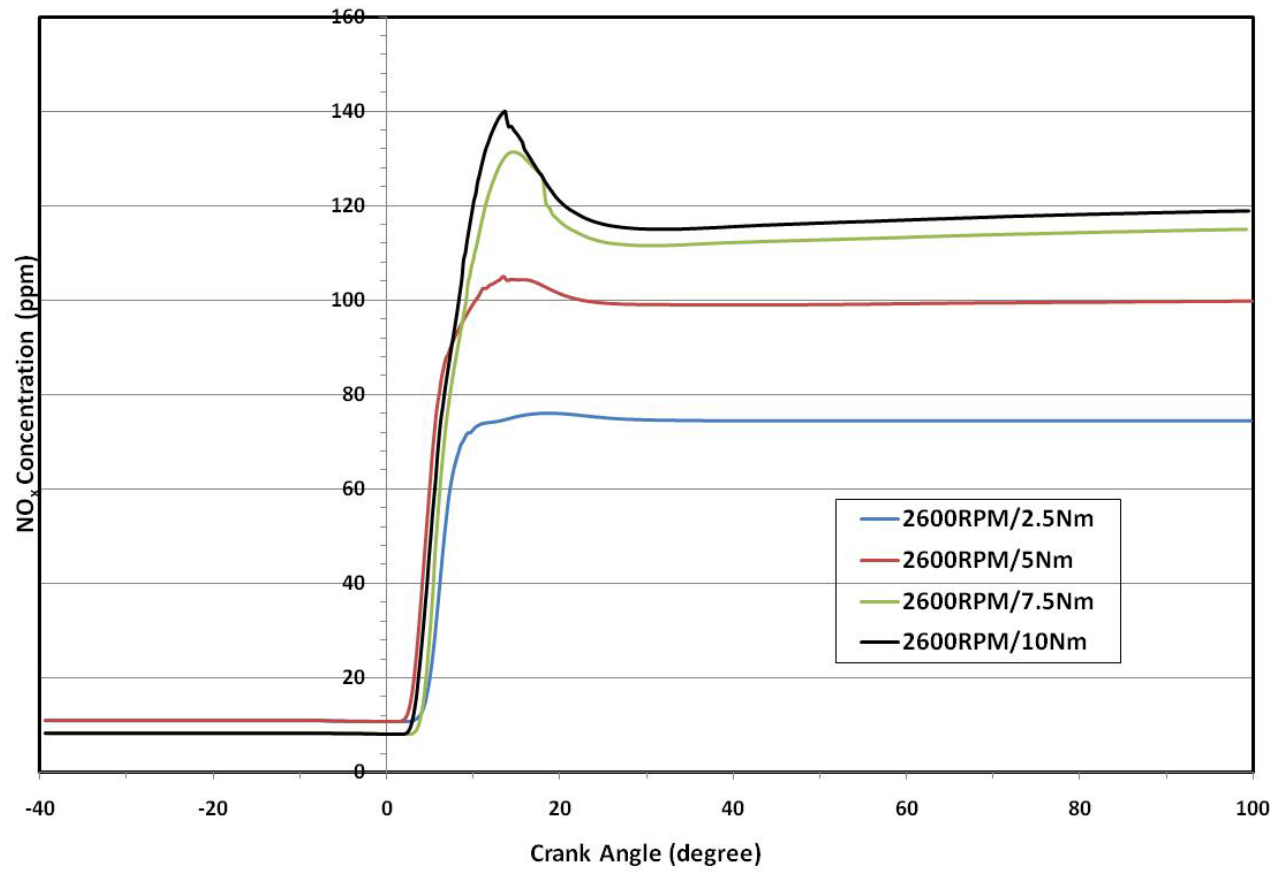

Figure 25. Simulation-predicted $\mathrm{NO}_{\mathrm{x}}$ concentration at engine speed of $2600 \mathrm{RPM}$ and engine loads of 2.5/5/7.5/10 Nm (No. 2 diesel fuel)

For the No. 2 diesel fuel, the test-measured and simulation-predicted combustion emissions concentrations of $\mathrm{NO}_{\mathrm{x}}, \mathrm{HC}, \mathrm{CO}$, and $\mathrm{CO}_{2}$ are summarized and compared in tables 2 and 3 . In these two tables, the $\mathrm{A} / \mathrm{F}$ and Lambda stand for air-to-fuel ratio and excess air ratio, respectively; the emissions concentration values included in the parentheses are simulation-predicted results.

Table 2. Comparison between test-measured and simulation-predicted emissions for No. 2 diesel fuel at engine speed of $2200 \mathrm{rpm}$

\begin{tabular}{|c|c|c|c|c|c|c|c|c|c|}
\hline $\begin{array}{c}\text { Engine speed } \\
(\mathbf{r p m})\end{array}$ & $\begin{array}{c}\text { Torque } \\
(\mathbf{N m})\end{array}$ & $\begin{array}{c}\mathbf{N O}_{\mathbf{x}} \\
(\mathbf{p p m})\end{array}$ & $\begin{array}{c}\mathbf{C O} \\
(\mathbf{p p m})\end{array}$ & $\begin{array}{c}\mathrm{HC} \\
(\mathbf{p p m})\end{array}$ & $\begin{array}{c}\mathbf{C O}_{2} \\
(\mathbf{p p m})\end{array}$ & $\mathbf{A} / \mathbf{F}$ & $\begin{array}{c}\mathbf{O}_{2} \\
(\% \mathrm{vol})\end{array}$ & Lambda & $\begin{array}{c}\text { Injected fuel } \\
\text { mass per cycle } \\
(\mathbf{m g})\end{array}$ \\
\hline 2200 & 2.5 & $\begin{array}{c}92 \\
(81)\end{array}$ & $\begin{array}{c}300 \\
(5030)\end{array}$ & $\begin{array}{c}20 \\
(96)\end{array}$ & $\begin{array}{c}26400 \\
(32985)\end{array}$ & 95.7 & 17.64 & 6.57 & 6.622 \\
\hline 2200 & 5 & $\begin{array}{c}104 \\
(132)\end{array}$ & $\begin{array}{c}400 \\
(4842)\end{array}$ & $\begin{array}{c}22 \\
(70)\end{array}$ & $\begin{array}{c}36600 \\
(61610)\end{array}$ & 67.6 & 16.35 & 4.62 & 11.982 \\
\hline 2200 & 7.5 & $\begin{array}{c}119 \\
(155)\end{array}$ & $\begin{array}{c}700 \\
(5747)\end{array}$ & $\begin{array}{c}24 \\
(51)\end{array}$ & $\begin{array}{c}48800 \\
(81534)\end{array}$ & 47.2 & 14.16 & 3.22 & 16.119 \\
\hline
\end{tabular}

(Note: emissions concentration values included in parentheses are simulation-predicted results.) 
Table 3. Comparison between test-measured and simulation-predicted emissions for No. 2 diesel fuel at engine speed of $2600 \mathrm{rpm}$

\begin{tabular}{|c|c|c|c|c|c|c|c|c|c|}
\hline $\begin{array}{c}\text { Engine speed } \\
(\mathbf{r p m})\end{array}$ & $\begin{array}{c}\text { Torque } \\
(\mathbf{N m})\end{array}$ & $\begin{array}{c}\mathbf{N O}_{\mathbf{x}} \\
(\mathbf{p p m})\end{array}$ & $\begin{array}{c}\mathbf{C O} \\
(\mathbf{p p m})\end{array}$ & $\begin{array}{c}\mathrm{HC} \\
(\mathbf{p p m})\end{array}$ & $\begin{array}{c}\mathrm{CO}_{2} \\
(\mathbf{p p m})\end{array}$ & $\mathbf{A} / \mathbf{F}$ & $\begin{array}{c}\mathbf{O}_{2} \\
(\% \text { vol) }\end{array}$ & Lambda & $\begin{array}{c}\text { Injected fuel } \\
\text { mass per cycle } \\
(\mathbf{m g})\end{array}$ \\
\hline 2600 & 2.5 & $\begin{array}{c}67 \\
(74)\end{array}$ & $\begin{array}{c}400 \\
(10681)\end{array}$ & $\begin{array}{c}24 \\
(287)\end{array}$ & $\begin{array}{c}26200 \\
(32725)\end{array}$ & 105 & 17.85 & 7.25 & 7.774 \\
\hline 2600 & 5 & $\begin{array}{c}99 \\
(100)\end{array}$ & $\begin{array}{c}500 \\
(9951)\end{array}$ & $\begin{array}{c}24 \\
(192)\end{array}$ & $\begin{array}{c}41600 \\
(54304)\end{array}$ & 59.8 & 15.5 & 4.23 & 11.528 \\
\hline 2600 & 7.5 & $\begin{array}{c}129 \\
(116)\end{array}$ & $\begin{array}{c}1100 \\
(7840)\end{array}$ & $\begin{array}{c}24 \\
(46)\end{array}$ & $\begin{array}{c}61000 \\
(95367)\end{array}$ & 42.9 & 13.5 & 2.93 & 18.936 \\
\hline 2600 & 10 & $\begin{array}{c}146 \\
(120)\end{array}$ & $\begin{array}{c}3800 \\
(10824)\end{array}$ & $\begin{array}{c}25 \\
(40)\end{array}$ & $\begin{array}{c}92600 \\
(100302)\end{array}$ & 28.1 & 9.78 & 1.93 & 20.557 \\
\hline
\end{tabular}

(Note: emissions concentration values included in parentheses are simulation-predicted results.)

Comparison between the simulation-predicted and test-measured emissions data shows relatively good agreement for the $\mathrm{NO}_{\mathrm{x}}$ emissions. In addition, the $\mathrm{CO}_{2}$ predictions were generally within a factor of two, but the results for $\mathrm{CO}$ and $\mathrm{HC}$ could differ by more than an order of magnitude under the conditions tested. This might be due to the fact that the predictive combustion simulation DIJet modeling is primarily developed in the GT-Power to predict the burn rate and $\mathrm{NO}_{\mathrm{x}}$ emissions. In this simulation approach, the $\mathrm{NO}_{\mathrm{x}}$ emissions are predicted using Extended Zeldovich mechanism, while the rest of emissions are primarily calculated using equilibrium chemistry.

Accurate emissions predictions are a challenge because they depend on accurate combustion simulation inputs and proper predictions of air flow, fuel flow, and burn rate. The limited accuracy of various fuel properties required in the combustion simulations is also considered as one of the reasons why there are still some large differences between predicted and measured emissions in some of the tests.

\section{5-CONCLUSIONS}

Engine combustion modeling and laboratory emissions testing for the conventional No. 2 diesel fuel have been performed and compared so that accurate emissions modeling tools can be established to predict diesel engine combustion emissions, which include regulated emissions of $\mathrm{NO}_{\mathrm{x}} / \mathrm{HC} / \mathrm{CO}$ and greenhouse gas of $\mathrm{CO}_{2}$, and to improve future engine designs. A unique feature and contribution of this study is the use of the fuel injector sac pressure profiles in the predictive combustion modeling and the testing technique developed in the laboratory for the fuel injector sac pressure measurement.

The fuel injector sac pressure is difficult to measure due to difficult accessibility, very high pressure, and high frequency response required. A pair of fast response absolute pressure transducers was installed on the fuel injection line of the test engine, and the sac pressure was then calculated using industry standard calculations. The fuel injector sac pressure profile is a critical GT-Power simulation input which has profound influences on the predicted engine performances and emissions concentrations. It appears that 
reasonable agreement on the combustion emissions between simulations and testing, for some constituents, has been achieved in this study when the measured fuel injector sac pressure profiles were utilized as combustion simulation inputs at various engine speed-load combinations.

\section{ACKNOWLEDGMENT}

This work was supported by the United States Environmental Protection Agency under Grant \# XA833795-01-0.

\section{REFERENCES}

1. United States Department of Energy's Office of Science, "Basic Research Needs for Clean and Efficient Combustion of $21^{\text {st }}$ Century Transportation Fuels," Report of the Basic Energy Sciences Workshop on Clean and Efficient Combustion of $21^{\text {st }}$ Century Transportation Fuels, 2006.

2. Manley, D. K., Mcllroy, A., Taatjes, C. A., "Research Needs for Future Internal Combustion Engines,” Physics Today, November 2008.

3. Srivastava, A. and Prasad, R., "Triglycerides-Based Diesel Fuels,” Renewable and Sustainable Energy Reviews, 2000.

4. Ruan, D. F., Cheng, W. L., and Lee, C. F., "Comparison of Performance and Combustion Characteristics of Diesel Fuel and Vegetable Oils in DI Diesel Engine,” 2008 SAE International Powertrains, Fuels and Lubricants Congress, Shanghai, China, June 23-25, 2008.

5. McCrady, J., Hansen, A., and Lee, C. F., “Modeling Biodiesel Combustion Using GT-Power,” 2007 ASABE Annual International Meeting, Minneapolis, Minnesota, June 17-20, 2007.

6. McCrady, J., Hansen, A., and Lee, C. F., "Combustion and Emissions Modeling of Biodiesel Using GT-Power,” 2008 ASABE Annual International Meeting, Providence, Rhode Island, June 29 - July 2, 2008.

7. Gamma Technologies, GT-Power User’s Manual (Version 6.2), September 2006.

8. Takenaka, N., Kadowaki, T., Kawabata, Y., Lim, I. C., and Sim, C. M., "Visualization of Cavitation Phenomena in a Diesel Engine Fuel Injection Nozzle by Neutron Radiography,” Nuclear Instruments and Methods in Physics Research, Section A 542, 2005.

9. Abdul Rahim Ismail, Semin and Rosli Abu Bakar, "Valve Flow Discharge Coefficient Investigation for Intake and Exhaust Port of Four Stroke Diesel Engines,” Journal of Engineering and Applied Sciences 2 (12), 2007. 